\title{
Popliteal Fossa
}

National Cancer Institute

\section{Source}

National Cancer Institute. Popliteal Fossa. NCI Thesaurus. Code C103222.

A diamond-shaped depression located in the back of the knee joint. 